\title{
Nightmares in children with FASD, ASD and their typically developing peers.
}

\author{
Rabya Mughal ${ }^{1 *}$, Siu Sing Wong ${ }^{1}$, Dagmara Dimitriou ${ }^{1}$, Elizabeth Halstead ${ }^{1}$
}

1 Sleep Education and Research Laboratory, Department of Psychology and Human Development, UCL Institute of Education, London WC1H 0AA, UK.

* Correspondence: rabya.mughal@ucl.ac.uk

\begin{abstract}
Children with Fetal Alcohol Spectrum Disorders (FASD) and Autism Spectrum Disorders (ASD) experience significantly higher rates of sleep disturbances than their typically developing peers. Pre-sleep anxiety and waking emotional content is known to affect the content and frequency of nightmares, which can be distressing to children and caregivers. This is the first study to analyse nightmare frequency and content in FASD, and to assess its association with psychometric outcomes. We assessed reports from 277 caregivers of children with ASD (n=61), FASD (n=112), and TD children ( $\mathrm{n}=104)$ using the Children's Sleep Habits Questionnaire (CSHQ), the Child Behavior Checklist (CBCL), the Spence Children's Anxiety Scale (SCAS) and the Behavior Rating Inventory for Executive Functioning (BRIEF). Within the ASD group, $40.3 \%$ of caregivers reported their children had nightmares. Within the FASD group, $73.62 \%$ of caregivers reported their children had nightmares and within the TD group, $21.36 \%$ of caregivers reported their children had nightmares. Correlation analysis revealed significant associations between anxiety and nightmares, maladaptive behaviour and nightmares, and executive functioning and nightmares in the TD and FASD groups, but not ASD group. This paper adds to the emerging body of work supporting the need for sleep interventions as part of clinical practice with regard to children with ASD and FASD. As a relatively niche but important area of study this warrants much needed further research.
\end{abstract}

Keywords: Sleep, neurodevelopment, nightmares, dreaming, Autism, Fetal Alcohol Spectrum Disorders.

\section{Introduction}

During Rapid Eye Movement (REM) sleep, it is thought that brainstem generators phasically activate motor, perceptual, affective, cognitive and amnestic circuits whose information is then synthesised into what is known as dreaming [1]. The sequential operation of non-REM (NREM) and REM sleep throughout the night is crucial for a fully functioning cognitive system [2-3], and is fundamental to the cognitive and emotional development of the child [4]. Contextualised within the wider remit of sleep-associated neuromechanics, NREM is associated with the strengthening of episodic and executive memory consolidation whilst REM is associated with both memory as well as affect-based information consolidation using shared neural pathways consistent with emotional, abstract and creative mental content [2]. It is for this reason that REM sleep is associated with vivid, emotional and bizarre dreams, whilst NREM sleep is associated with real, fragmented content that is continuous with waking life [5-8]. However dreams in general tend to be reported within REM sleep $[9,10]$, with over $90 \%$ reported when awakening from REM sleep, versus $43 \%$ reported when waking from NREM sleep [10].

Nightmares are defined as disturbing mental experiences that awaken the dreamer and generally occur in REM sleep [11], alongside typical negative emotions of terror, fear, and anxiety $[12,13]$. First nightmare experiences tend to be at around three years old, peaking between six and ten years old [14-16]. As reported by Floress et al., [17], the nightmare frequency of children is associated with higher levels of anxiety as rated by caregivers. 
Furthermore nightmare frequency is associated with the mood regulation function of dreaming [18], suggesting nightmares occur as a result of intense pre-sleep negative emotions. Moreover, nightmares may prompt bedtime worries and anxiety and can therefore result in bedtime resistance behavioural problems [17], such as leaving the bedroom, stalling bedtimes or the need to fall asleep next to the parent [4]. It is also reasonable to note the bidirectional relation between nightmare frequency and child anxiety [19]. Indeed, night time fears, anxiety and recurrent nightmares are commonly presented problems in paediatric sleep, particularly in children with significant trauma [20]. In paediatric populations, negative affect and trauma is connected to both associative and hyperassociative nightmares [21].

Chronological age is usually a compounding factor relating to nightmare frequency. Younger typically developing (TD) children tend to have more active imaginations and are likely to have fantastic-associated nightmares (such as zombies, monsters, witches etc.) whereas older TD children and adolescents are more likely to have realistic and wakecongruous nightmares (such as school, academic performance, friendship problems etc.) [20]. Meanwhile, the age related changes in children's dreams appear to parallel emotional and cognitive development since the older children become, the more they are able to describe the frequency and length of dreams and provide detailed descriptions [22]. This raises methodological questions as to the accuracy of such data collection, which relies on accurate recollection upon waking and is more reliable at home than in a laboratory setting $[23,24]$. Nonetheless, the intensity of emotions experienced upon waking can be more accurately reflected by children and caregivers as this tends to be more subjective, which is pertinent to the study of nightmares in paediatric populations. In one study by Resnick \& Stickgold [24] a sample of 88 children aged between 4 and 10 years old, familiar settings, bizarreness and family members including the child themselves were more likely to be reported in dream recall upon waking, with aggression and intensity of emotion increasing with age. Sandor, Szakadat, Kertesz \& Bodizs [25] reported in their study of 40 children aged between 4 and 8 years, whose caregivers were trained to capture sleep related data over a period of six weeks, that $59 \%$ of dreams were reported as 'positive', $27 \%$ 'negative' and $14 \%$ as 'neutral'. Sandor et al. [25] also reported an increase in negative dreams with increasing age. Furthermore, nightmares in TD children are associated with a range of socioeconomic and psychometric outcomes [26]. In one large scale study by Xin Li et al. $(n=6359$; mean age $[\mathrm{SD}]=9.2$ [1.8]) of children from mainstream schools in China, $5.2 \%$ of caregivers of children reported their children experienced nightmares at least once a week, with nightmare frequency significantly associated with socioeconomic criteria (such as family income) and psychometric outcomes such as frequent temper outbursts, mood disturbance, hyperactivity as well as school performance. The question then remains as to nightmare frequency and psychometric correlates in children with atypical emotional and cognitive development. In children with neurodevelopmental conditions there is a scarcity of data on nightmare content, frequency and hyperassociation.

Autism Spectrum Disorders (ASD), are neurodevelopmental conditions characterised by social and communication difficulties, repetitive behaviour and sensory sensitivities [27]. Children with ASD have a higher occurrence of sleep disorders, anxiety and emotional regulation difficulties than their typically developing peers [28], which is associated with cognition and affect in this population [29]. Insomnia, parasomnias and disrupted sleep are significantly higher in ASD [30] and significantly associated with hyperactivity, aggression [31], affect [32] behavioural and social adaptive difficulties [33], cognition [34], communication difficulties [35] and academic performance [36]. However the phenotypic presentation of nightmares in this population is less clear. Adults with ASD are reported to experience fewer nightmares than controls [37] whilst in paediatric ASD populations the incidence of parasomnias is higher [29], but nightmare frequency is variable in comparison to controls [37], with one study by Chou and colleagues [38] assessing 345 children with ASD, controls and siblings finding that siblings were more likely to experience nightmares than controls or the clinical population [38]. 
Fetal Alcohol Spectrum Disorder (FASD) is the neurodevelopmental and physical consequence of prenatal alcohol exposure, manifesting in a pattern of executive functioning, social functioning, sensory perception and learning difficulties. Syndromic physical features may also be present [39]. Children with FASD are significantly more likely to experience trauma, attachment disorders and anxiety disorders than typically developing children the result of both pervasive cortical thinning due to prenatal alcohol exposure as well as epigenetic influences as a result of environmental stressors [40]. Around $80 \%$ of children with FASD are in the care of adults other than the biological parent, which contributes to attachment and attentional and other pervasive neurodevelopmental problems [41]. Sleep problems are prevalent in children with FASD and are thought to have a bidirectional association with neuropsychological outcomes such as sensory sensitivity [42], anxiety [43] and cognition [44]. Caregiver reports reveal that children with FASD present with significantly more sleep problems than TD children [45]. Caregiver report, polysomnography (PSG) and actigraphy studies report that children with FASD have significantly shorter sleep duration, lower sleep efficiency, more sleep disruption and more sleep disordered breathing and higher nightmare frequency than TD children [45].

The purpose of this study was to take an exploratory approach to assess the content of nightmares and their associated outcomes. Our aims were to report whether children with the two neurodevelopmental conditions, ASD and FASD were more likely to experience nightmares, and whether there is a correlational trend between nightmare content and psychometric outcomes of affect, behaviour or executive control.

\section{Materials and Methods}

\subsection{Ethical approval}

This study was approved by the UCL Institute of Education Research Ethics Committee (Approval number 16683/001). All caregiver participants gave written informed consent.

\subsection{Materials}

This study used several questionnaires to assess parental reported sleep and daytime functioning, and relevant background information of the child.

Children's Sleep Habits Questionnaire (CSHQ; [46]): A 33-item caregiver report which screens for common sleep problems in school aged children. It is rated on a 3 point scale ('rarely' for an event that occurs 0-1 times per week; 'sometimes' for an event that occurs 2-4 times per week; 'usually' for an event that occurs between 5-7 times per week). The CSHQ is a widely used assessment tool in paediatric sleep with high internal validity and Cronbach Alpha score of 0.83 [47]. Items are grouped into eight subscales: Bedtime Resistance, Sleep Onset Delay, Sleep Duration, Sleep Anxiety, Night Waking, Parasomnia, Sleep Disordered Breathing, Daytime Sleepiness. Clinical scores are determined as 41 or above. Nightmare frequency and content was taken from Subscale Item 6: Parasomnias ("Does your child have nightmares? If so, describe the frequency and content").

Spence Children's Anxiety Scale (SCAS; [48]): A 39-item caregiver report which screens for clinical anxiety levels in children aged between 6 and 16. It is rated on a 4-point scale $(0=$ Never to $3=$ Always). The SCAS is a widely used instrument with high internal validity and a Cronbach's Alpha score of 0.92 . The SCAS assesses various anxiety symptoms specified in the DSM-V including subscales for Separation Anxiety, Social Phobia, Obsessive-Compulsive Disorder, Panic, Physical Injury Fears and Generalised Anxiety Disorder. Clinical scores are determined as 31 and above [49].

Behavior Rating Inventory of Executive Function (BRIEF; [50]) An 83-item caregiverreport which screens for atypical executive functioning in children aged between 5 and 16 years. It is rated on a 3 -point scale $(1=$ Never to $3=$ Often). The BRIEF Is a widely used measurement of executive functioning with a Cronbach Alpha score of 0.8-0.98. Eight aspects of executive functioning are assessed. Subscales are Working Memory, Inhibition, 
Shifting, Emotional Control, and Planning and Organisation. Clinical scores are determined as 65 and above [50].

Child Behavior Checklist (CBCL; [51]). A 118 item caregiver report which measures maladaptive behaviours in children aged between 5 and 16. It is rated on a 3-point scale $(0=$ Not true to $2=$ Very true). The CBCL is widely used in research settings with mental health workers, hospital staff, foster parents, clinicians, and teachers. It has high internal validity, with a 0.94 Cronbach's Alpha score. Subscales are divided into 'Internalising' and 'Externalising' behaviours as well as the Subsets of: Withdrawn, Somatic Complaints, Anxious/ Depressed, Social Problems, Thought Problems, Attention Problems, Delinquency and Aggression. Clinical scores are determined as a total of 64 and above [52].

The Childhood Autism Rating Scale, Parents Version (CARS; [53]). A 15-item caregiver questionnaire that screens for the severity of autistic symptoms, using a seven point (including midpoint) Likert Scale, ranging from typical to atypical behaviour. Categories are: relating to people, imitation, emotional responsiveness, body use, object use, adaptation to change, visual responses, listening responses, taste, smell, touch responses, fear or nervousness, verbal communication, nonverbal communication, activity levels, intellectual responsiveness and general observations. The CARS demonstrates moderate to good sensitivity and specificity ( $81.4 \%$ and $78.6 \%$ respectively) and good internal consistency (Cronbach's Alpha $=0.79$ ) however cannot be used in place of a diagnostic assessment. A CARS score of $>=33$ indicates possible ASD [54].

Neurobehavioural Screening Tool (NST; [55]). A ten-item binary checklist that screens for possible FASD in children. Questions examine whether children meet the more common neurobehavioural characteristics of FASD, however these are not always accurate or representative of all children with FASD. Categories are: acting young, lying and cheating, lacking guilt after misbehaving, difficulty concentrating, impulsivity, hyperactivity, displays of cruelty, stealing at home, and stealing outside of home. The NST has low sensitivity but high specificity (62\% and $100 \%$ respectively) and in the absence of a more accurate measurement tool, is a widely used screening mechanism for FASD in children. Scores above 8, plus confirmed prenatal alcohol exposure indicate a FASD diagnostic evaluation should be conducted [55].

\subsection{Participants}

Participants were caregivers of children aged between 6 and 15 years old (between the $6^{\text {th }}$ and $16^{\text {th }}$ birthday). This age group was chosen since it represents a large age range from which a cross sectional analysis could be made.

All children had received either a diagnosis of FASD, ASD, and no diagnoses of any physical or mental health conditions in the TD group. Screening tools for FASD and ASD were additionally included in the battery of questionnaires that caregivers completed. A number of children also had secondary diagnoses, which are outlined in Table 1 below.

This study was initially advertised as an online questionnaire assessing sleep and daytime functioning in children with FASD or ASD. Caregivers of TD participants were recruited through three schools in West London, South London, and Milton Keynes. Caregivers of children with FASD were recruited through the UK FASD Network mailing list, while caregivers of children with ASD were recruited through online ASD forums. Caregivers were directed to an online questionnaire, at the end of which there was an option to receive feedback on the child's score, as well as sleep hygiene intervention ideas.

A total of 322 caregivers completed the online questionnaire. Nine responses were excluded as large sections of the questionnaire were not completed. Twenty-four responses were excluded as they did not have a diagnosis of FASD or ASD, and were not TD. A further 12 were excluded as they did not meet the age criteria. One- way between group ANOVAs indicated no age $\left(\mathrm{F}(1,235)=1.06, p=0.43, \eta_{\mathrm{p}}{ }^{2}=0.85\right)$ or SES differences $\left(\mathrm{F}(1,3)=1.06, p=0.49, \eta_{\mathrm{p}}^{2}=0.01\right)$ but there were significant differences between sex, with significantly more boys than girls $\left(F(1,2)=6.58, p=0.01, \eta_{p}{ }^{2}=0.02\right)$. The final sample consisted of 277 participants, outlined in Table 1. 
Table 1: Participant details

\begin{tabular}{lccc}
\hline & ASD & FASD & TD \\
\hline$n$ & 61 & 112 & 104 \\
Male/Female & $46 / 15$ & $62 / 50$ & $55 / 48$ \\
Age (M(SD)) & $10.03(2.54)$ & $9.54(2.86)$ & $9.43(2.55)$ \\
Age Range & $6.07-15.56$ & $6.09-15.98$ & $6.47-15.90$ \\
SES 1/2/3 & $17 / 35 / 9$ & $14 / 74 / 26$ & $23 / 67 / 15$ \\
\hline
\end{tabular}

\subsection{Statistical analysis}

We performed quantitative methodology using SPSS Statistics for Windows, Version 23.0 (IBM SPSS Statistics for Windows, Version 23.0. Armonk, NY: IBM Corp). The questionnaire had a $92 \%$ response rate with 146 missing values. Where there were missing data, these were imputed in SPSS. One-way ANOVA with Gabriel post-hoc tests were conducted to examine group differences of nightmare frequency, child sleep habits, child anxiety, executive function and behaviour. Pearson's correlation coefficient was performed to test if the nightmare frequency was associated with clinical outcome measures. Qualitative content analysis was conducted using NVivo V.12 on novel items which could not be categorised into the Garfield [56] and Shredl \& Pallmer [57] categorisation of 'being chased' 'injury or death' or sensing scary'.

\section{Results}

\subsection{Thematic Analysis of Nightmare Themes}

Table 2 shows the percentage of children whose nightmare content fell into the categories of 'being chased', 'injury or death' and 'sensing scary' as reported by Garfield [56] and Schredl and Pallmer [57].

Table 2. Nightmare content reported by caregivers

\begin{tabular}{|c|c|c|c|c|c|c|}
\hline & \multicolumn{2}{|c|}{$\begin{array}{l}\text { ASD } \\
\mathrm{n}=67\end{array}$} & \multicolumn{2}{|c|}{$\begin{array}{l}\text { FASD } \\
\mathrm{n}=91\end{array}$} & \multicolumn{2}{|c|}{$\begin{array}{c}\text { TD } \\
\mathrm{n}=103\end{array}$} \\
\hline Being chased & $2 / 27$ & $7 \%$ & $10 / 67$ & $15 \%$ & $1 / 22$ & $5 \%$ \\
\hline Injured/dying & $3 / 27$ & $11 \%$ & $4 / 67$ & $6 \%$ & $2 / 22$ & $9 \%$ \\
\hline Sensing scary & $1 / 27$ & $4 \%$ & $1 / 67$ & $1 \%$ & $0 / 22$ & $0 \%$ \\
\hline
\end{tabular}

Table 3 shows the characters each group experienced within the three themes. Children in the TD group reported being chased by a 'dog' whilst children in the clinical groups reported being chased by more fantastic characters such as 'aliens', 'monsters' or 'large insects'. Similarly whilst TD children reported dreaming of the death of 'people' and 'puppies', the children from the ASD and FASD groups had dreamed of the death of unusual characters like 'toys' and 'aliens' or significant family members. Children in the FASD group were the only ones to dream of concrete characters (e.g., witches) in the nightmare theme of 'sensing scary'.

Table 3. Dream characters in typical nightmare themes

\begin{tabular}{lccc} 
& Being Chased & Injured/dying & Sensing scary \\
\hline \multirow{2}{*}{ ASD } & Aliens & Wolves, & \\
FASD & Wolves, monsters, strangers, someone, & Aliens, family members, themselves" & People, mum, toys, dogs \\
\hline
\end{tabular}




\section{large insects}

Table 4 presents the results of thematic analysis based on the nightmare themes of Gakenbach [58] and Revonsuo and Salmivalli [59]. Nightmare content from the FASD group was classified into the theme of fantasy (30\%), persecuted/being chased (18\%), and robbery/theft/crime (9\%) but less for the theme of real life (9\%), while the pattern was somewhat similar between the TD and ASD groups. A full list of nightmare content can be found in the Appendix.

\begin{tabular}{|c|c|c|c|c|c|c|}
\hline & Separation & Fantasy & $\begin{array}{c}\text { Persecuted /being } \\
\text { chased }\end{array}$ & Real life & $\begin{array}{c}\text { Death/injury/ vio- } \\
\text { lence }\end{array}$ & $\begin{array}{c}\text { Robbery/ Theft/ } \\
\text { Crime }\end{array}$ \\
\hline $\mathrm{TD}(\mathrm{n})$ & 3 & 3 & 2 & 3 & 2 & 0 \\
\hline TD (\%) & $23 \%$ & $23 \%$ & $15 \%$ & $23 \%$ & $15 \%$ & $0 \%$ \\
\hline FASD (n) & 11 & 17 & 10 & 5 & 11 & 5 \\
\hline FASD (\%) & $24 \%$ & $30 \%$ & $22 \%$ & $9 \%$ & $24 \%$ & $9 \%$ \\
\hline ASD (n) & 4 & 4 & 2 & 4 & 4 & 0 \\
\hline ASD (\%) & $22 \%$ & $22 \%$ & $11 \%$ & $22 \%$ & $22 \%$ & $0 \%$ \\
\hline
\end{tabular}

\subsection{Group Comparison on Nightmare Frequency and All Clinical Outcome Measures}

One-way ANOVA with the Gabriel post-hoc test was conducted to examine if nightmare frequency, child sleep habit, child anxiety, behaviour and executive function varied between the three groups. Under the timeframe from 'less than monthly (1)' to 'nightly (5)', nightmare frequency was significantly varied among the three groups $(\mathrm{F}(2$, $\left.58)=7.142, \mathrm{p}=.002, \eta^{2}=0.203\right)$, with the children from the TD group $(\mathrm{M}=2.25, \mathrm{SD}=1.06)$ scoring significantly lower in nightmare frequency than the ASD group $(\mathrm{M}=3.57, \mathrm{SD}=$ $1.09, \mathrm{p}=.009)$ and the FASD group $(\mathrm{M}=3.58, \mathrm{SD}=1.09, \mathrm{p}=.001)$ while there were no differences of nightmare frequency between the ASD and FASD groups.

As Table 5 shows, the omnibus $F$ test of one-way ANOVA showed the significant group differences on the total CSHQ $\left(\mathrm{F}(2,115)=6.842, \mathrm{p}=.002, \eta^{2}=0.108\right)$, total SCAS $(\mathrm{F}(2$, $\left.115)=6.842, p=.002, \eta^{2}=0.108\right)$, total $\operatorname{CBCL}\left(F(2,115)=19.735, p<.001, \eta^{2}=0.259\right)$ and total BRIEF (Welch's F $(2,40.867)=22.018, \mathrm{p}<.001)$. Specifically, the results of the Gabriel posthoc test indicated that the children in the TD group scored significantly lower than both the ASD and FASD groups whilst there were no differences found between the ASD and FASD groups. These patterns of findings were also found in subscales of the CSHQ, SCAS, CBCL, BRIEF, but not the obsessive-compulsive scale of the SCAS, or withdrawn, anxious/depressed, social problems, delinquency externalising behaviours, and aggression externalising behaviours within the CBCL.

Table 5. Group differences on CSHQ, SCAS, CBCL, BRIEF

\begin{tabular}{|c|c|c|c|c|c|c|c|}
\hline & ASD & FASD & $\mathrm{TD}$ & & $\begin{array}{c}\text { TD vs. } \\
\text { ASD }\end{array}$ & $\begin{array}{l}\text { TD vs. } \\
\text { FASD }\end{array}$ & $\begin{array}{c}\text { ASD vs. } \\
\text { FASD }\end{array}$ \\
\hline & Mean $(S D)$ & Mean $(S D)$ & Mean $(S D)$ & $F$ & Sig. & & \\
\hline \multicolumn{8}{|c|}{ CSHQ } \\
\hline Total & $\begin{array}{l}55.59 \\
(9.22)\end{array}$ & $\begin{array}{l}56.01 \\
(8.53)\end{array}$ & $\begin{array}{l}48.27 \\
(8.65)\end{array}$ & $6.842^{* *}$ & .012 & .001 & .995 \\
\hline
\end{tabular}




\begin{tabular}{|c|c|c|c|c|c|c|c|}
\hline Bedtime resistance & $\begin{array}{c}9.63 \\
(3.10)\end{array}$ & $\begin{array}{l}9.19 \\
(2.74)\end{array}$ & $\begin{array}{c}9.27 \\
(2.66)\end{array}$ & .233 & .960 & .999 & .865 \\
\hline Sleep onset delay & $\begin{array}{c}4.74 \\
(2.46)\end{array}$ & $\begin{array}{l}5.15 \\
(2.73)\end{array}$ & $\begin{array}{c}3.86 \\
(2.08)\end{array}$ & 2.108 & .548 & .104 & .853 \\
\hline Sleep duration & $\begin{array}{c}7.74 \\
(1.35)\end{array}$ & $\begin{array}{l}7.43 \\
(1.52)\end{array}$ & $\begin{array}{c}7.73 \\
(1.12)\end{array}$ & .645 & 1.000 & .762 & .697 \\
\hline Sleep anxiety & $\begin{array}{c}8.93 \\
(2.77)\end{array}$ & $\begin{array}{l}8.91 \\
(3.24)\end{array}$ & $\begin{array}{c}5.73 \\
(2.33)\end{array}$ & $10.157^{* * *}$ & .001 & .001 & 1.000 \\
\hline Night wakings & $\begin{array}{c}7.74 \\
(3.27)\end{array}$ & $\begin{array}{c}7.64 \\
(2.80)\end{array}$ & $\begin{array}{c}4.95 \\
(2.44)\end{array}$ & $8.090^{* *}$ & .003 & .001 & .998 \\
\hline Parasomnias & $\begin{array}{c}7.74 \\
(3.19)\end{array}$ & $\begin{array}{l}8.01 \\
(3.29)\end{array}$ & $\begin{array}{c}8.05 \\
(4.10)\end{array}$ & .070 & .986 & 1.000 & .978 \\
\hline Sleep disordered breathing & $\begin{array}{c}2.78 \\
(1.31)\end{array}$ & $\begin{array}{l}2.79 \\
(1.11)\end{array}$ & $\begin{array}{c}2.50 \\
(1.37)\end{array}$ & .504 & .808 & .673 & 1.000 \\
\hline Daytime sleepiness & $\begin{array}{c}7.70 \\
(3.21)\end{array}$ & $\begin{array}{l}7.85 \\
(3.77)\end{array}$ & $\begin{array}{c}7.68 \\
(4.19)\end{array}$ & .025 & 1.000 & .997 & .997 \\
\hline \multicolumn{8}{|l|}{ SCAS } \\
\hline Total & $\begin{array}{c}43.04 \\
(16.15)\end{array}$ & $\begin{array}{c}43.58 \\
(17.34)\end{array}$ & $\begin{array}{c}29.36 \\
(17.93)\end{array}$ & $5.977^{* *}$ & .019 & .002 & .999 \\
\hline Panic Attack & $\begin{array}{c}6.11 \\
(5.57)\end{array}$ & $\begin{array}{c}6.45 \\
(4.30)\end{array}$ & $\begin{array}{c}2.73 \\
(3.49)\end{array}$ & $5.841^{* *}$ & .029 & .002 & .982 \\
\hline Separation Anxiety & $\begin{array}{c}9.30 \\
(3.71)\end{array}$ & $\begin{array}{c}9.75 \\
(3.98)\end{array}$ & $\begin{array}{c}6.50 \\
(4.10)\end{array}$ & $5.693^{* *}$ & .044 & .002 & .940 \\
\hline Physical Injury & $\begin{array}{c}6.04 \\
(3.20)\end{array}$ & $\begin{array}{c}6.24 \\
(3.02)\end{array}$ & $\begin{array}{c}4.59 \\
(2.72)\end{array}$ & 2.529 & .262 & .067 & .987 \\
\hline Social Phobia & $\begin{array}{c}7.33 \\
(3.08)\end{array}$ & $\begin{array}{c}8.60 \\
(4.63)\end{array}$ & $\begin{array}{c}7.05 \\
(4.59)\end{array}$ & 1.504 & .994 & .344 & .467 \\
\hline Obsessive Compulsive & $\begin{array}{c}5.81 \\
(3.73)\end{array}$ & $\begin{array}{c}4.81 \\
(3.49)\end{array}$ & $\begin{array}{c}2.86 \\
(3.09)\end{array}$ & $4.480^{*}$ & .011 & .059 & .476 \\
\hline Generalised Anxiety & $\begin{array}{c}8.44 \\
(3.83)\end{array}$ & $\begin{array}{c}7.75 \\
(3.53)\end{array}$ & $\begin{array}{c}5.64 \\
(3.80)\end{array}$ & $3.916^{*}$ & .025 & .048 & .774 \\
\hline T Score & $\begin{array}{l}65.37 \\
(4.11)\end{array}$ & $\begin{array}{l}65.12 \\
(5.06)\end{array}$ & $\begin{array}{c}57.41 \\
(15.11)\end{array}$ & $8.759^{* * *}$ & .002 & .001 & .999 \\
\hline \multicolumn{8}{|l|}{ CBCL } \\
\hline Total & $\begin{array}{c}64.41 \\
(21.88)\end{array}$ & $\begin{array}{c}77.82 \\
(25.71)\end{array}$ & $\begin{array}{c}39.27 \\
(26.96)\end{array}$ & $19.735^{* * *}$ & .002 & .000 & .053 \\
\hline Withdrawn & $\begin{array}{c}5.19 \\
(2.90)\end{array}$ & $\begin{array}{c}6.18 \\
(3.82)\end{array}$ & $\begin{array}{c}4.00 \\
(4.23)\end{array}$ & 3.012 & .605 & .043 & .543 \\
\hline Somatic Complaints & $\begin{array}{c}4.33 \\
(3.79)\end{array}$ & $\begin{array}{c}4.19 \\
(3.06)\end{array}$ & $(2.32)^{* * * *}$ & $7.526^{* *}$ & .004 & .001 & .996 \\
\hline Anxious Depressed & $\begin{array}{l}11.89 \\
(6.14)\end{array}$ & $\begin{array}{l}11.97 \\
(6.55)\end{array}$ & $\begin{array}{c}7.73 \\
(7.12)\end{array}$ & $3.680^{*}$ & .085 & .022 & 1.000 \\
\hline Social Problems & 6.22 & 8.12 & 3.55 & $22.587^{* * *}$ & .004 & .001 & .009 \\
\hline
\end{tabular}




\begin{tabular}{|c|c|c|c|c|c|c|c|}
\hline & $(2.61)$ & $(2.86)$ & $(2.94)$ & & & & \\
\hline Thought Problems & $\begin{array}{c}5.37 \\
(3.15)\end{array}$ & $\begin{array}{c}5.27 \\
(2.74)\end{array}$ & $\begin{array}{c}2.55 \\
(2.48)\end{array}$ & $8.655^{* * *}$ & .002 & .001 & .998 \\
\hline Attention Problems & $\begin{array}{l}10.93 \\
(3.74)\end{array}$ & $\begin{array}{l}12.97 \\
(3.68)\end{array}$ & $\begin{array}{c}5.82 \\
(4.34)\end{array}$ & $29.009^{* * *}$ & .001 & .001 & .053 \\
\hline Delinquency Externalizing & $\begin{array}{c}3.52 \\
(3.17)\end{array}$ & $\begin{array}{c}6.31 \\
(3.89)\end{array}$ & $\begin{array}{c}2.50 \\
(2.41)\end{array}$ & $12.746^{* * *}$ & .673 & .001 & .001 \\
\hline Aggression Externalizing & $\begin{array}{l}16.96 \\
(7.94)\end{array}$ & $\begin{array}{l}22.81 \\
(8.51)\end{array}$ & $\begin{array}{l}11.77 \\
(8.01)\end{array}$ & $16.136^{* * *}$ & .090 & .001 & .006 \\
\hline \multicolumn{8}{|l|}{ BRIEF } \\
\hline Total & $\begin{array}{l}175.07 \\
(25.32)\end{array}$ & $\begin{array}{l}181.43 \\
(21.52)\end{array}$ & $\begin{array}{l}128.32 \\
(35.14)\end{array}$ & $36.817^{* * *}$ & .001 & .001 & .599 \\
\hline Working Memory & $\begin{array}{c}71.70 \\
(11.37)\end{array}$ & $\begin{array}{c}74.22 \\
(10.71)\end{array}$ & $\begin{array}{c}56.57 \\
(12.95)\end{array}$ & $19.528^{* * *}$ & .001 & .001 & .689 \\
\hline Shifting & $\begin{array}{c}76.44 \\
(13.15)\end{array}$ & $\begin{array}{c}78.59 \\
(12.57)\end{array}$ & $\begin{array}{c}56.81 \\
(14.88)\end{array}$ & $22.279^{* * *}$ & .001 & .001 & .848 \\
\hline Planning and Organising & $\begin{array}{c}68.41 \\
(10.46)\end{array}$ & $\begin{array}{c}72.17 \\
(10.18)\end{array}$ & $\begin{array}{c}55.29 \\
(14.60)\end{array}$ & $18.038^{* * *}$ & .000 & .000 & .355 \\
\hline Organisation of Materials & $\begin{array}{l}60.07 \\
(8.46)\end{array}$ & $\begin{array}{c}61.25 \\
(11.34)\end{array}$ & $\begin{array}{c}49.00 \\
(12.76)\end{array}$ & $10.068^{* * *}$ & .002 & .000 & .951 \\
\hline Monitoring & $\begin{array}{l}67.74 \\
(9.51)\end{array}$ & $\begin{array}{l}69.70 \\
(9.93)\end{array}$ & $\begin{array}{c}51.52 \\
(14.22)\end{array}$ & $23.152^{* * *}$ & .000 & .000 & .801 \\
\hline Inhibition & $\begin{array}{c}70.44 \\
(11.09)\end{array}$ & $\begin{array}{c}70.53 \\
(11.09)\end{array}$ & $\begin{array}{c}55.76 \\
(15.07)\end{array}$ & $13.058^{* * *}$ & .000 & .000 & 1.000 \\
\hline Initiate & $\begin{array}{l}69.44 \\
(9.85)\end{array}$ & $\begin{array}{c}68.66 \\
(13.25)\end{array}$ & $\begin{array}{c}52.57 \\
(12.77)\end{array}$ & $14.734^{* * *}$ & .000 & .000 & .989 \\
\hline Emotional Control & $\begin{array}{c}71.89 \\
(11.14)\end{array}$ & $\begin{array}{c}70.17 \\
(13.32)\end{array}$ & $\begin{array}{c}56.24 \\
(14.41)\end{array}$ & $10.620^{* * *}$ & .000 & & .913 \\
\hline
\end{tabular}

\subsection{The Relation between Nightmare Frequency and Clinical Outcome Measures}

Pearson's correlation coefficient with bootstrapping was conducted to examine whether nightmare frequency associated with any of the clinical outcome measures in each group of children. As Table 6 shows, the nightmare frequency of TD children was positively significantly associated with maladaptive behaviour and executive function, while the nightmare frequency of the children from the FASD group was positively significantly related to child maladaptive behaviour and anxiety. No correlations were found withing the ASD group.

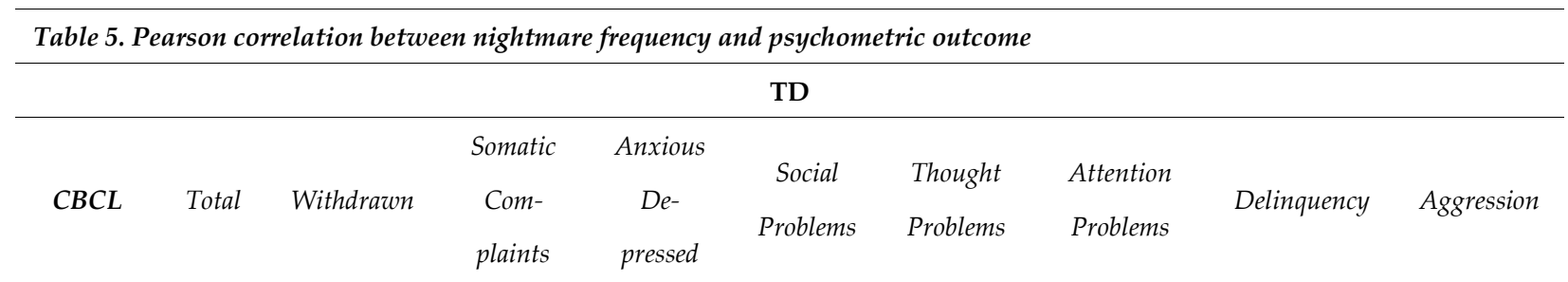




\begin{tabular}{|c|c|c|c|c|c|c|c|c|c|}
\hline & $.799^{* * *}$ & .468 & $.594^{*}$ & $.768^{* *}$ & .306 & $.668^{*}$ & $.807^{* *}$ & .344 & .698 \\
\hline \multirow{3}{*}{ BRIEF } & \multirow{2}{*}{ Total } & Working & \multirow{2}{*}{ Shifting } & Planning & Organise & \multirow{2}{*}{ Monitor } & \multirow{2}{*}{ Inhibition } & \multirow{2}{*}{ Initiate } & \\
\hline & & Memory & & Organise & Materials & & & & Control \\
\hline & $.638^{*}$ & $.648^{*}$ & $.624^{*}$ & $.615^{*}$ & .101 & .575 & .405 & $.836^{* *}$ & $.683^{*}$ \\
\hline \multicolumn{10}{|c|}{ FASD } \\
\hline \multirow{4}{*}{$C B C L$} & \multirow{3}{*}{ Total } & \multirow{3}{*}{ Withdrawn } & Somatic & Anxious & & & & \multirow{3}{*}{ Delinquency } & \multirow{3}{*}{ Aggression } \\
\hline & & & Com- & $D e-$ & soctal & 1nought & Allen & & \\
\hline & & & plaints & pressed & Problems & Problems & Problems & & \\
\hline & $.444^{*}$ & $.502^{* *}$ & $.358^{*}$ & $.405^{*}$ & .318 & $.453^{* *}$ & $.353^{*}$ & .238 & .171 \\
\hline \multirow{3}{*}{ SCAS } & & Panic At- & Separa- & Physical & Social & Obsess/ & Generalized & \multirow[b]{2}{*}{ T Score } & \\
\hline & Total & tack & $\begin{array}{l}\text { tion Anx- } \\
\text { iety }\end{array}$ & Injury & Phobia & $\begin{array}{l}\text { Compul- } \\
\text { sive }\end{array}$ & & & \\
\hline & .353 & $.413^{*}$ & .138 & .232 & .128 & .289 & .342 & $.352^{*}$ & \\
\hline
\end{tabular}

Note. All the bias-corrected and accelerated (BCa) bootstrapped confidence interval did not contain "zero"

${ }^{*} p<.05 .{ }^{* *} p<.01 .{ }^{* * * *} p<.001$

\section{Discussion}

This is the first study to explore the associations between nightmares and psychometric outcomes in children with ASD, FASD and in TD children. We aimed to explore nightmare frequency and content among the three groups, as well as correlational associations between nightmare frequency, anxiety, maladaptive behaviour and executive functioning in children with ASD, children with FASD and TD children. Children in both clinical groups scored significantly higher on anxiety, maladaptive behaviour and executive functioning measures than their TD peers. Children in both clinical groups experienced significantly more sleep problems than the TD group. Within our sample, children with ASD and FASD had significantly more nightmares than TD children: Seventy four percent of children in the FASD group were reported to have nightmares; $40 \%$ of the ASD group were reported to have nightmares, which was in comparison to $21 \%$ reported in the TD group. Nine percent of the TD group reported to have weekly nightmares, which is comparable to previous data which reported weekly nightmares in $5.2 \%$ of a sample of 6359 TD children [26]. In addition, we report that within our sample nightmare frequency was significantly associated with maladaptive behaviour and anxiety in children with FASD. Nightmare frequency was also significantly associated with maladaptive behaviour and executive functioning difficulties TD children. These results demonstrate much needed further investigation into this area of research.

\subsection{Nightmare Content}

Children in the TD group were more likely to report nightmares involving insects and dogs. This is in line with previous studies in TD populations reporting frequent appearances of animals in children's dreams [22]. Children in the ASD group reported more death, injury and violence related nightmares than the TD group, but also similar amounts of real life, being chased, fantasy and separation related nightmares. Children in the ASD group were more likely to report nightmares of themselves being injured, whereas children in the TD and FASD groups were more likely to report nightmares of significant others being injured. In one comparison study between children with ASD, siblings and a control group $(\mathrm{n}=345)$, Chou and colleagues [38] noted that bringing up experience, i.e. having more than one caregiver and changing caregivers frequently, was positively associated with nightmare frequency [38]. This could perhaps be an explanation for the higher number of appearances of attachment figures within the FASD nightmares, as well as higher frequency of nightmares in the FASD group. Children in the FASD group 
reported the most robbery, theft and crime related nightmares, persecutory nightmares such as being chased (usually by wolves, monsters or strangers), separation nightmares, and nightmares involving people, toys or animals with significance being injured, dying or taken away. According to the Threat Simulation Theory, threatening experiences during wake are rehearsed during sleep, possibly due to dream consciousness working as an evolutionary defence mechanism, in which the brain repeatedly simulates threatening events [59]. Children with FASD are significantly more likely to experience attachment issues as a result of upbringing differences, including the frequent changing of caregivers. This may explain why threatening situations such as being chased or family members dying were rehearsed by children with FASD. Meanwhile, injury to self was more prominent in children in the ASD group which could perhaps be due to the 'self - other' perception within ASD [60].

\subsection{Nightmare frequency and psychometric associations.}

In the TD group, nightmare frequency was significantly associated with composite CBCL scores, as well as the subscales of anxious and depressed behaviour, attentional problems, aggression. Nightmare frequency was significantly associated with composite BRIEF scores, as well as the subscales of working memory, shifting, planning and organising, initiation and emotional control. In the FASD group, nightmare frequency was significantly correlated with composite CBCL scores, as well as the subscales of withdrawn, somatic, anxious/ depressed, and thought problems. Nightmare frequency was also significantly associated with total SCAS as well as the subscale of panic symptoms. No associations were found within the ASD group. In one narrative review by Lemyre et al. [37], nightmare frequency was reported to be positively related to psychiatric outcomes such as posttraumatic stress, depressive, bipolar, anxiety and obsessive compulsive disorders, but not in ASD where they report the association between nightmares and psychometric outcomes is less clear. In this narrative review, adults with ASD were reported to have significantly fewer nightmares than controls and there appeared to be no relationship between ASD and nightmares in children and adolescents [37]. Inconsistent to previously reported data on nightmares in children with ASD, our study reports that children with ASD experienced a significantly higher number of nightmares than their TD peers. The frequency of nightmares has previously been positively associated with ASD symptomology and IQ [31] but not to psychometric outcomes, whilst parasomnias in general have previously been reported to have various associations with psychometric outcomes, some positive, some non-conclusive [29]. This is consistent with our findings. This nonlinear relationship may be due to lower scores on the CBCL, SCAS and BRIEF in contrast to the ceiling effect noted below.

This lack of association in the ASD group may also be due to the processes involved in emotional regulation and hypersensation. Higher emotional regulation difficulty is associated with higher nightmare frequency in light of the influence of waking intense emotions [61] and the theory of the adaptive emotion regulation function in dreaming [22]. Based upon these findings, emotion regulation difficulty could be the underlying factor for the nightmare frequency in the ASD group, in which difficulties in emotion regulation are well reported [28]. In addition, hypersensitisation in ASD may be a contributory factor. Early adverse experiences during sensitive windows can have a longlasting effect on nightmare frequency, that is, a trait variable maybe associated with sensory processing sensitivity and a trait marker encompassing increased emotional reactivity, greater depth of processing, and subtle awareness of environment stimuli. Experiences resulting from hypersensation can be distressful and contribute to the occurrence of nightmare according to the Continuity Hypothesis in which negative experiences in waking life transfer to dreaming, alongside intense negative emotions before sleep [61]. In addition, according to the nightmare theory of the selective mood regulatory function of dreaming [62], the occurrence of nightmares are due to the emotional surge in REM sleep that dreaming fails to adaptively regulate. Based on the findings demonstrating the disruption of REM sleep in ASD [63], it might be the case that 
REM disruption contributes to the failure of dreaming to adapt waking emotions which thereby lead to nightmares.

\subsection{CSHQ/ nightmare frequency}

Although nightmare frequency positively correlated with CBCL, BRIEF and SCAS in the TD and FASD groups, nightmare frequency was not associated with sleep related measurements from the CSHQ. These measure bedtime resistance, sleep onset delay, sleep anxiety, night waking, parasomnia, sleep disordered breathing and daytime sleepiness. This may be because CSHQ scores did not contribute to nightmare frequency as sleep quality is generally not a leading factor of nightmare frequency [22]. However within some subscales of the CSHQ, particularly sleep anxiety, night waking and parasomnias, caregivers were asked whether during pre-sleep children experienced negative affect, troubling thoughts - or whether children woke up at night screaming or inconsolable. It would have followed then, for these items within the CSHQ subscales to correlate with nightmare frequency. Perhaps due to the small number of participants who reported nightmares such data were not found, or this may be due to the ceiling effect of high nightmare frequency and high parasomnia scores. Within previous analyses of the larger dataset $[43,44]$, parasomnias were significantly associated with executive functioning and behavioural outcomes in the TD and FASD group, but less so in the ASD group. Night wakings however were associated with somatic complaints and attention in the TD group, which is comparable to the present analysis. However this result warrants further investigation.

\subsection{CBCL/ nightmare frequency}

In the TD group, nightmare frequency was significantly correlated with several CBCL subscores, particularly those related to affect. These were the subscales of anxious/ depressed, attention and aggression. In the FASD group, nightmare frequency was significantly correlated with withdrawn, somatic, anxious/ depressed and thought problems. Influential factors of negative emotions before sleep [18], the susceptibility of dreaming to waking intense emotions [23], as well as the theoretical models of continuity hypothesis and pre-sleep states as the behavioral problems displayed by children could explain the relationship between the manifestation of intense emotional experiences and nightmare frequency and content.

The CBCL assesses children's withdrawn, somatic, anxious, social, thought, attention, delinquency and aggressive behaviour, however the instrument itself is used differently between the two clinical groups. Due to the widespread neural damage incurred by prenatal alcohol exposure, children with FASD may have difficulties with a number of behaviours which are compounded by the environmental stressors common to the psychosocial environment [38]. Children with FASD therefore tend to score within clinical levels in a pattern like manner on the CBCL due to developmental, regulatory, affect based and executive functioning issues and as a result the CBCL is used as a screening tool for FASD [38]. Behavioural manifestations in ASD are not as homogenous and children with ASD present with wide range of internalised and externalised behaviours across the several subsections of the CBCL [64]. This heterogeneity may explain why CBCL scores were not associated with nightmare frequency in the ASD group. Within the TD group, the present results are comparable to previous data on nightmare frequency and aggression in children. In the previously mentioned large scale study by Xin Li et al. [25], nightmare frequency was significantly correlated with aggression, as well as mood disturbance and hyperactivity.

\subsection{SCAS/ nightmare frequency}

TD children were more likely to experience nightmares if they also scored within the clinical range of 'anxious/ depressed' within the CBCL. In the FASD group, SCAS total 
score and the subscale of panic symptoms were significantly correlated with nightmare frequency. Anxiety subscales measured panic symptoms, separation anxiety, physical injury fears, social anxiety, obsessive compulsive symptomology and generalised anxiety. It is reasonable to assume a relationship between anxiety and nightmare frequency given the involvement of pre-sleep emotions on the occurrence of nightmares, as well as the role of emotional continuity and threat simulation $[18,23,59]$. Anxiety is consistently associated with sleep problems both in children with ASD [28] and FASD [44]. In addition, nightmares are conceptualised as anxiety based phenomenon [61]. Additionally, nightmares are connected to emotional regulation [62], fear [65], repressed fear [66] and the transformation of shame into fear [67]. As mentioned above, threatening experiences during wake may be rehearsed during sleep which may explain why anxiety was significantly associated with nightmare frequency within our sample.

\subsection{BRIEF/ nightmare frequency}

Executive functioning related measurements that were measured related to working memory, emotional control, inhibition, monitoring, organisation of materials, planning and organising and shifting. Simor et al. 68 for example refer to the association between executive functioning and nightmare frequency due to impaired fronto-limbic functioning during REM sleep. It is interesting that this association was found only in the TD group and not the clinical groups, both of which are clinical conditions related to frontal lobe functioning, but this is likely due to a higher proportion of the clinical group already reaching maximum executive functioning scores and creating a ceiling effect which was not seen in the TD group.

\section{Strengths and Limitations}

This is the first study to report nightmare frequency and content in children with FASD. Sleep problems in ASD and FASD are currently understudied, particularly those pertaining to behavioural and affect based outcomes. Through further research such as this it may be possible to develop sleep interventions for children with neurodevelopmental conditions. This study additionally benefits from a large sample size from which nightmare data could be extracted, but further studies on nightmares in these clinical populations should take into consideration the smaller sub samples of children who experience nightmares. Some of the strengths of this study are within the large sample size, its novelty, and access to a relatively understudied population of children with FASD.

Several limitations are also of importance here. Firstly, parental reports are subjective views of children's sleep problems and further analysis can benefit from objective sleep measures such as actigraphy or polysomnography (PSG). Such objective investigations may be used to correlate PSG or actigraphy data with nightmare frequency or content. Secondly, the results reported here may be attributed to a selection bias in that parents of children with sleep problems were more likely to want to take part and the sample may not have the heterogeneity of a population-based sample. Around a third of participants had to be excluded because of the lack of a formal diagnosis of FASD or ASD due to a general lack or delay in diagnostic services available in the UK. Thirdly, predictions within this study are statistical descriptions. Without an experimental design and with the limits of cross-sectional data, causation cannot be implied. However, this study has provided a platform for the need for further examination using objective sleep and psychometric measures in these clinical populations.

\section{Summary}

We report that, analogous with theory, nightmares may be associated with waking emotions within children with ASD or FASD, although the causative, bidirectional associations are less clear. The cross-sectional nature of the present data means that any 
inference about direction of the associations between nightmares and psychometric outcomes can only be hypothetical and further analysis could possibly assess in greater depth nightmare content and frequency. We recommend that the development of sleep intervention strategies to reduce general anxiety, as well as affect, aggression, hyperactive and other maladaptive behaviours of the child during presleep activities and thereby reduce the occurrence of nightmares. 
Author Contributions: For research articles with several authors, a short paragraph specifying their individual contributions must be provided. The following statements should be used "Conceptualization, RM, SW, LH, DD; methodology, SW.; software SW.; validation, RM, SW, LH, DD; formal writing: RM, SW, LH, DD

Funding: This research received no external funding.

Institutional Review Board Statement: This study was approved by the UCL Institute of Education Research Ethics Committee (Approval number 16683/001). All caregiver participants gave written informed consent.

Informed Consent Statement: Informed consent was obtained from all subjects involved in the study

Data Availability Statement: All data pertaining to this paper can be found in Appendix A.

Conflicts of Interest: The authors declare no conflict of interest.

\section{Appendix A: All nightmare content.}

\begin{tabular}{|c|c|}
\hline Group & Does your child have nightmares? If so, please describe the content and frequency. \\
\hline $\mathrm{TD}$ & Random content. Could be me leaving could be monsters. Could be about going to school. Usually weekly. \\
\hline $\mathrm{TD}$ & Very rarely, last time she dreamed our puppy had died. \\
\hline $\mathrm{TD}$ & At least once a week, they tend to involve wolves, aliens or family members going away/being hurt. \\
\hline TD & $\begin{array}{l}\text { Rarely at the minute and usually he will get up out of bed but not fully awake, needs consoling but will go } \\
\text { back to bed easily and fall back to sleep. }\end{array}$ \\
\hline TD & $\begin{array}{l}\text { May call out for Mummy or Daddy once every couple of weeks. Will sometimes talk in sleep but make no } \\
\text { sense. }\end{array}$ \\
\hline TD & Occasionally about 1 a month. She can't remember the content. \\
\hline TD & $\begin{array}{l}\text { Yes, he is just been able to tell us that he dreams that monsters are eating people. More often he wakes crying } \\
\text { repeatedly (up to } 10 \text { times a night) calling for me and tells us that he feels sad. }\end{array}$ \\
\hline $\mathrm{TD}$ & $\begin{array}{l}\text { Nothing I would call a nightmare, but she calls them nightmares. They sound like random dreams, with } \\
\text { some running away. }\end{array}$ \\
\hline TD & Separation monthly. \\
\hline $\mathrm{TD}$ & Dead people, ghosts, it can happen a couple of times per month. \\
\hline $\mathrm{TD}$ & Every now and then. Normally about something happening to close family or the pets. \\
\hline $\mathrm{TD}$ & $\begin{array}{l}\text { The content can vary, and he doesn't always remember. Depending on our routine they are infrequent as he } \\
\text { suffers from night terrors, so we monitor things closely. }\end{array}$ \\
\hline $\mathrm{TD}$ & Very often most nights speak about being chased by a dog. \\
\hline $\mathrm{TD}$ & School worries. \\
\hline $\mathrm{TD}$ & Sporadic. Maybe every $3-5$ weeks. No regular pattern. Sometimes link to tv. \\
\hline $\mathrm{TD}$ & Once a year maybe. Sometimes involving monsters. \\
\hline $\mathrm{TD}$ & He has nightmares very sporadically, but he doesn't want to talk about them. \\
\hline $\mathrm{TD}$ & Occasional due to anxiety, issues at school and stress of preparing for GCSE's. \\
\hline FASD & Crying screaming thrashing about not often. \\
\hline FASD & Sometimes, alone, Vikings. \\
\hline FASD & He sometimes has nightmares. Maybe once a week. \\
\hline
\end{tabular}


FASD

FASD

FASD

FASD

FASD

FASD

FASD

FASD

FASD

FASD

FASD

FASD

FASD

FASD

FASD

FASD

FASD

FASD

FASD

FASD

FASD

FASD

FASD

FASD

FASD

FASD

FASD

FASD

FASD

FASD

FASD

FASD

FASD

FASD

FASD
Yes. Every night. She wakes up screaming and sweating at least once. She seems phased out and will not talk she will however follow instructions. She can't remember what her nightmares are about and will not talk about them the next day.

Few times a month for a few consecutive nights then none for a while. Content is not clear.

Occasional nightmares, something that may be worrying him.

Occasionally.

Yes. Always monsters chasing him. Usually once or twice a week.

Yes, related to past experiences, about 2-4 times per week.

He tells me he has nightmares most nights. He dreams people die or he dies. He dreams he is alone and can't find anyone. He feels he can't come and get me or call out for help as he thinks there are people in the house who will come and kill him.

Occasionally about monsters and zombies.

Regularly. Scary witches. Ghosts.

One every 2 or so weeks. Dreams of being taken by a stranger.

Once twice a month, she can never remember but she's shouting at somebody in her sleep.

Being chased, maybe twice a week.

Sometimes, being chased or chasing, fighting others, knives or clowns. Less frequent in last year and a half.

She will shout out in her sleep and talks a lot.

Usually involving boys fighting over her, once a week.

Has nocturnal epilepsy. Used to have when younger. Now has waking fear palpitation.

Yes, more than 2 to 3 times a week.

None that he talks about.

Yes - vivid dreams about zombies and monsters are common.

She can't tell me the content. 5 times a week approx.

Maybe, but she cannot tell us.

House break in.

Not sure, will sometimes wake up very upset.

Being 'robbed' from me.

Not often. Once a month perhaps. Often dreams foxes have eaten our chickens. Or a fox jumps into his bedroom window. Or fox staring at him through his 2 nd floor bedroom window. Sometimes dreams of giants smashing things up in his bedroom. Or dreams of thieves breaking in and stealing his toys and precious cuddly toys. Sometimes monsters or dinosaurs.

Rarely but if does being chased.

Yes, but she is unable to explain the content.

Yes, and wets bed at same time. Content is varied but can be being chased, about once a month it wakes her up.

Yes, about twice a week he will have bad dream. He is usually shouting 'get off me' and pleading. We go and stroke his head and tell he's at home in bed and is safe.

Yes 1-week approx. The past.

Sometimes not as frequent at the moment but talks a lot in his sleep.

Not as bad recently. Used to wake and be inconsolable, sometimes self-harming.

Approx. Twice a week. Usually about bad guys or monsters.

Occasionally no idea what they are about she says bad guys.

Occasionally.....Mum dying. 
FASD

FASD

FASD

FASD

FASD

FASD

FASD

FASD

FASD

FASD

FASD

FASD

FASD

FASD

FASD

FASD

FASD

FASD

FASD

FASD

FASD

AUTISM

AUTISM

AUTISM

AUTISM

AUTISM

AUTISM

AUTISM

AUTISM

AUTISM

Yes, big presence in his room, disturbed by noise.

Not being able to get something.

2-3 per month he tells me he has had a nightmare, maybe has them more but doesn't say. They always seem to be about him, his brother and his mum but he can't explain anymore. Suffered neglect while living with mother because of drug and alcohol misuse.

Sometimes but not clear what the nightmare was about as she doesn't remember, or she can't describe it. Sometimes he will say I had a bad dream last night.

Monsters people in his head telling him to do bad things. At least once a week.

They have reduced following two and a half years of psychotherapy, but they are nightmares of red buttons, trolls, robots.

Yes, less frequently now, but approx. Every 3 weeks or so. He is unable to tell us the content.

Not that he says, he's only mentioned a few in the past but can't remember them

Yes. Very abstract not very specific.

Possibly 3-4 times a month Usually someone chasing him or catching him.

Yes, quite regular, about his siblings, the dog, his toys dying.

Usually twice a week shouting n muttering in sleep is noted but child will not recall a nightmare. Once a fortnight usually a nightmare about her safety or my safety.

Yes, he does. Can be very large insects chasing him. Being killed, shot.

Every night.

Every night. Mostly about me dying or there being people in the house that will kill him. Lots of his nightmares don't make sense.

Most night. Dreams about skeletons or the monster that eats babies that lives at school.

Most nights. Used to be an insomniac before going on risperidone.

Every night not recalled.

Monsters 2 times a week.

Yes at least once a week often every night. People or monsters chasing him.

Not sure if he has nightmares but he shouts out throughout the night and tosses and turns.

1 per week but has gone through phases of having lots. V scared of dark so often needs lights on or gets the fear when wakes at night. When he wakes after midnight, he rarely seems that sleepy and I'm not sure he's going to go back to sleep. He seems v alert.

Rarely, cannot recall content.

Yes often. He doesn't usually want to say but he often dreams of someone in the family or him dying. He goes through phases where he will have nightmares and night terrors every night and other phase where he doesn't have them for a while. He doesn't like closing his eyes or want to go to sleep for fear of nightmares and if he has one in the night, he won't go back to sleep for fear of it happening again.

Yes - almost every night. He doesn't want to describe it when he wakes. Later he may say it's about some-

thing from TV or event that's happened. He struggles to switch off the fear and so needs us to sleep with him to get back and stay asleep.

Yes, about once a week, they are always linked to abandonment- being left at a railway station or about waking and no one else being at home.

Yes. And infrequent once a week if that.

Aliens are coming to get him!

She says she has usually if someone has shown her something or she has seen something by accident. Can be 3-4 times a week or none. No pattern. Gets scared by noises. 


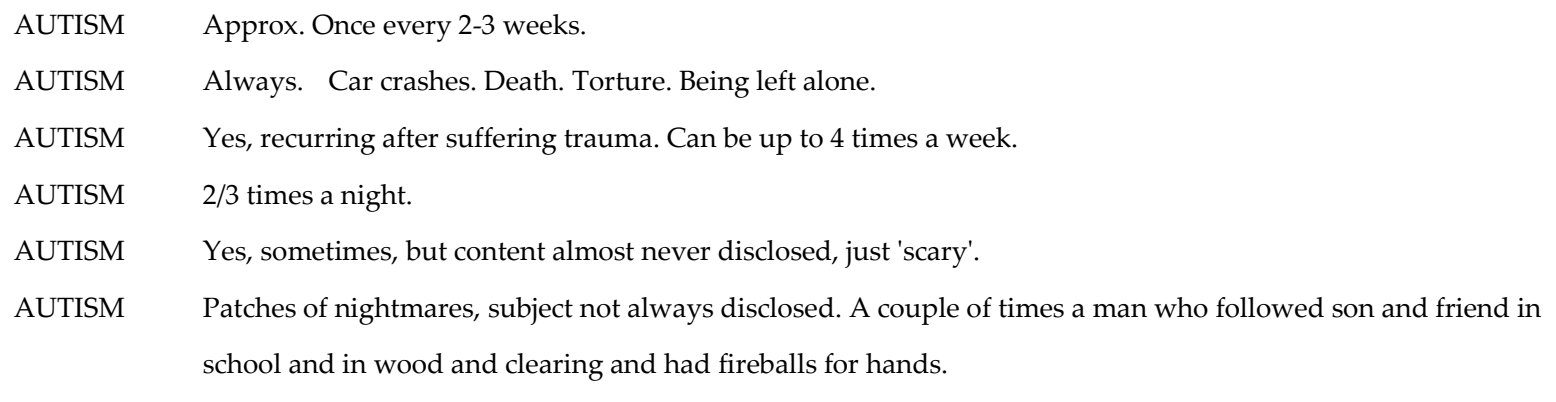

AUTISM I think he sometimes has nightmares, but he is unable to explain the content of his dreams. This occurs probably 2 or 3 times a week.

AUTISM Sometimes he does; he rarely remembers but they seem to involve him being chased. He went through a rough patch when someone at school told him about 'Five Nights at Freddie's', he was anxious and had nightmares about that for a while.

AUTISM Nightmares 2-3 times a week usually of some form of harm happening to family member.

AUTISM Sometimes - only a few times a month. He does talk in his sleep though and sleep walk more frequently.

AUTISM Over past few months since starting high school has been happening about 10 times a month.

AUTISM Yes, probably 2 to 3 times a week. Sometimes night terrors but this is lessening with age.

AUTISM Apparently most nights but he can't describe them.

AUTISM Occasional nightmare about being lost and unable to find people or being chased by wolves.

AUTISM Wakes crying saying had bad dream a hand full of times a year.

1. Sheldon, S. H., Ferber, R., Kryger, M. H., \& Gozal, D. (Eds.). (2014). Principles and practice of pediatric sleep medicine e-book. Elsevier Health Sciences.

2. Heller, J., Brcina, N., Dogan, I., Holtbernd, F., Romanzetti, S., Schulz, J. B., ... \& Reetz, K. (2017). Brain imaging findings in idiopathic REM sleep behavior disorder (RBD)-a systematic review on potential biomarkers for neurodegeneration. Sleep medicine reviews, 34, 23-33.

3. Dement, W., \& Greenberg, S. (1966). Changes in total amount of stage four sleep as a function of partial sleep deprivation. Electroencephalography and Clinical Neurophysiology, 20(5), 523-526.

4. Mindell, J. A., \& Owens, J. A. (2015). A clinical guide to pediatric sleep: diagnosis and management of sleep problems. Lippincott Williams \& Wilkins.

5. Foulkes, D. (1967). Nonrapid eye movement mentation. Experimental Neurology.

6. Foulkes, D., \& Rechtschaffen, A. (1964). Presleep determinants of dream content: Effects of two films. Perceptual and Motor Skills, 19(3), 983-1005.

7. Merritt, J. M., Stickgold, R., Pace-Schott, E., Williams, J., \& Hobson, J. A. (1994). Emotion profiles in the dreams of men and women. Consciousness and Cognition, 3(1), 46-60.

8. Rechtschaffen, A., Verdone, P., \& Wheaton, J. (1963). V. Reports of mental activity during sleep. Canadian Psychiatric Association Journal, 8(6), 409-414.

9. Fosse, R., Stickgold, R., \& Hobson, J. A. (2001). Brain-mind states: reciprocal variation in thoughts and hallucinations. Psychological science, 12(1), 30-36.

10. Nielsen, T. A. (2000). A review of mentation in REM and NREM sleep:"covert" REM sleep as a possible reconciliation of two opposing models. Behavioral and Brain Sciences, 23(6), 851-866.

11. American Academy of Sleep Medicine. (2014). The international classification of sleep disorders (ICSD-3). Darien, CT: AASM.

12. Belicki, K., \& Cuddy, M. A. (1991). Nightmares: Facts, fictions and future directions. In J. Gackenbach \& A. A. Sheikh (Eds.), Dream images: A call to mental arms (pp. 99-113). Amityville, NY: Baywood Publishing

13. Zadra, A., Pilon, M., \& Donderi, D. C. (2006). Variety and intensity of emotions in nightmares and bad dreams. The Journal of nervous and mental disease, 194(4), 249-254.

14. Fisher, B. E., \& Wilson, A. E. (1987). Selected sleep disturbances in school children reported by parents: prevalence, interrelationships, behavioral correlates and parental attributions. Perceptual and Motor Skills, 64(3_suppl), 1147-1157.

15. Muris, P., Merckelbach, H., Ollendick, T. H., King, N. J., \& Bogie, N. (2001). Children's nighttime fears: Parent-child ratings of frequency, content, origins, coping behaviors and severity. Behaviour research and therapy, 39(1), 13-28.

16. Simard, V., Nielsen, T. A., Tremblay, R. E., Boivin, M., \& Montplaisir, J. Y. (2008). Longitudinal study of bad dreams in preschool-aged children: prevalence, demographic correlates, risk and protective factors. Sleep, 31(1), 62-70. 
17. Floress, M. T., Kuhn, B. R., Bernas, R. S., \& Dandurand, M. (2016). Nightmare prevalence, distress, and anxiety among young children. Dreaming, 26(4), 280-292.

18. Cartwright, R. (2005). Dreaming as a mood regulation system. In M. H. Kryger, T. Roth, W. C. Dement (eds.), Principles and practice of sleep medicine ( $4^{\text {th }}$ ed., pp. 565-572). Philadelphia, PA: W.B. Saunders.

19. Reynolds, K. C., \& Alfano, C. A. (2016). Things that go bump in the night: frequency and predictors of nightmares in anxious and nonanxious children. Behavioral sleep medicine, 14(4), 442-456.

20. Meltzer, L. J., \& McLaughlin Crabtree, V. (2015). Pediatric sleep problems: A clinician's guide to behavioral interventions. American Psychological Association.

21. Schredl, M., \& Pallmer, R. (1998). Geschlechtsspezifische Unterschiede in Angstträumen von Schülerinnen und Schülern [Gender differences in anxiety dreams of school-aged children]. Praxis der Kinderpsychologie und Kinderpsychiatrie, 47(7), 463-476.

22. Moorcroft, W. H. (2013). Dreams. In Understanding Sleep and Dreaming (pp. 143-170). Springer, Boston, MA.

23. Malinowski, J., \& Horton, C. L. (2014). Evidence for the preferential incorporation of emotional waking-life experiences into dreams. Dreaming, 24(1), 18.

24. Resnick, J., Stickgold, R., Rittenhouse, C. D., \& Hobson, J. A. (1994). Self-representation and bizarreness in children' s dream reports collected in the home setting. Consciousness and Cognition, 3(1), 30-45.

25. Sándor, P., Szakadát, S., Kertész, K., \& Bódizs, R. (2015). Content analysis of 4 to 8 year-old children's dream reports. Frontiers in Psychology, 6, 534.

26. Li, S. X., Yu, M. W. M., Lam, S. P., Zhang, J., Li, A. M., Lai, K. Y. C., \& Wing, Y. K. (2011). Frequent nightmares in children: familial aggregation and associations with parent-reported behavioral and mood problems. Sleep, 34(4), 487-493.

27. American Psychiatric Association. (2013). Diagnostic and Statistical Manual of Mental Disorders (DSM). CoDAS.

28. Fletcher-Watson, S., \& Happé, F. (2019). Autism: A new introduction to psychological theory and current debate. Routledge.

29. Díaz-Román, A., Zhang, J., Delorme, R., Beggiato, A., \& Cortese, S. (2018). Sleep in youth with autism spectrum disorders: systematic review and meta-analysis of subjective and objective studies. Evidence-based mental health, 21(4), 146-154.

30. Calhoun, S. L., Pearl, A. M., Fernandez-Mendoza, J., Durica, K. C., Mayes, S. D., \& Murray, M. J. (2019). Sleep Disturbances Increase the Impact of Working Memory Deficits on Learning Problems in Adolescents with High-Functioning Autism Spectrum Disorder. Journal of Autism and Developmental Disorders. https://doi.org/10.1007/s10803-019-03928-y

31. Mayes, S. D., \& Calhoun, S. L. (2009). Variables related to sleep problems in children with autism. Research in Autism Spectrum Disorders. https://doi.org/10.1016/j.rasd.2009.04.002

32. Hundley RJ, Shui A, Malow BA. Relationship Between Subtypes of Restricted and Repetitive Behaviors and Sleep Disturbance in Autism Spectrum Disorder. J Autism Dev Disord. 2016

33. Sikora DM, Johnson K, Clemons T, Katz T. The relationship between sleep problems and daytime behavior in children of different ages with autism spectrum disorders. Pediatrics. 2012

34. Gabriels RL, Cuccaro ML, Hill DE, Ivers BJ, Goldson E. Repetitive behaviors in autism: Relationships with associated clinical features. Res Dev Disabil. 2005

35. Schreck KA, Mulick JA, Smith AF. Sleep problems as possible predictors of intensified symptoms of autism. Res Dev Disabil. 2004

36. Limoges É, Bolduc C, Berthiaume C, Mottron L, Godbout R. Relationship between poor sleep and daytime cognitive performance in young adults with autism. Res Dev Disabil. 2013

37. Lemyre, A., Bastien, C., \& Vallières, A. (2019). Nightmares in mental disorders: A review. Dreaming, $29(2), 144$.

38. Chou, M. C., Chou, W. J., Chiang, H. L., Wu, Y. Y., Lee, J. C., Wong, C. C., \& Gau, S. S. F. (2012). Sleep problems among Taiwanese children with autism, their siblings and typically developing children. Research in Autism Spectrum Disorders, 6(2), 665-672.

39. Astley SJ. Validation of the fetal alcohol spectrum disorder (FASD) 4-Digit diagnostic code. J Popul Ther Clin Pharmacol. 2013;20(3).

40. Warren, K. R., Hewitt, B. G., Thomas, J. D., May, P. A., Gossage, J. P., Chen, W. J. A., ... \& Sowell, E. R. Fetal alcohol spectrum disorders. research challenges and opportunities, 2011, 34.

41. Gagnier, K. R., Moore, T. E., \& Green, J. M. (2011). A need for closer examination of FASD by the criminal justice system: Has the call been answered?. Journal of Population Therapeutics and Clinical Pharmacology, 18(3).

42. Wengel, T., Hanlon-Dearman, A. C., \& Fjeldsted, B. (2011). Sleep and sensory characteristics in young children with fetal alcohol spectrum disorder. Journal of Developmental \& Behavioral Pediatrics, 32(5), 384-392.

43. Mughal, R., Joyce, A., Hill, C., \& Dimitriou, D. (2020). Sleep disturbance as a predictor of anxiety in children with Fetal Alcohol Spectrum Disorders and typically developing children. Research in developmental disabilities, 101, 103610.

44. Mughal, R., Hill, C. M., Joyce, A., \& Dimitriou, D. (2020). Sleep and cognition in children with fetal alcohol spectrum disorders (FASD) and children with autism spectrum disorders (ASD). Brain Sciences, 10(11), 863.

45. Chen, M. L., Olson, H. C., Picciano, J. F., Starr, J. R., \& Owens, J. (2012). Sleep problems in children with fetal alcohol spectrum disorders. Journal of Clinical Sleep Medicine, 8(4), 421-429.

46. Owens, J. A., Spirito, A., \& McGuinn, M. (2000). The Children's Sleep Habits Questionnaire (CSHQ): psychometric properties of a survey instrument for school-aged children. Sleep-New York-, 23(8), 1043-1052.

47. Markovich AN, Gendron MA, Corkum PV. Validating the Children's Sleep Habits Questionnaire against polysomnography and actigraphy in school-aged children. Front Psychiatry. 2015;6(JAN).

48. Spence SH. Structure of anxiety symptoms among children: a confirmatory factor-analytic study. J Abnorm Psychol. 1997;106(2):280-97. 
49. Essau CA, Muris P, Ederer EM. Reliability and validity of the Spence Children's Anxiety Scale and the Screen for Child Anxiety Related Emotional Disorders in German children. J Behav Ther Exp Psychiatry. 2002;33(1):1-18.

50. Roth RM, Isquith PK, Gioia GA. Assessment of executive functioning using the behavior rating inventory of executive function (BRIEF). In: Handbook of Executive Functioning. 2014.

51. Achenbach TM, Rescorla L a. Manual for the ASEBA Adult Forms \& Profiles. English. 2003.

52. Bean T, Mooijart A, Eurelings-Bontekoe E, Spinhoven P. Validation of the child behavior checklist for guardians of unaccompanied refugee minors. Child Youth Serv Rev. 2006;28(8):867-87.

53. Lord C, Schopler E. Neurobiological Implications of Sex Differences in Autism. In: Neurobiological Issues in Autism. 1987.

54. Garfin DG, McCallon D. Validity and reliability of the Childhood Autism Rating Scale with autistic adolescents. J Autism Dev Disord. 1988.

55. Nash, K., Koren, G., \& Rovet, J. (2011). A differential approach for examining the behavioral phenotype of fetal alcohol spectrum disorders. Journal of Population Therapeutics and Clinical Pharmacology, 18(3).

56. Garfield, P. (1984) Your child's Dreams. New York: Ballentine..

57. Schredl, M., \& Pallmer, R. (1998). Geschlechtsspezifische Unterschiede in Angstträumen von Schülerinnen und Schülern [Gender differences in anxiety dreams of school-aged children]. Praxis der Kinderpsychologie und Kinderpsychiatrie, 47(7), 463-476.

58. Gackenbach, J. (2006). Video game play and lucid dreams: Implications for the development of consciousness. Dreaming, 16(2), 96.

59. Revonsuo, A., \& Salmivalli, C. (1995). A content analysis of bizarre elements in dreams. Dreaming, 5(3), 169.

60. Huang, A. X., Hughes, T. L., Sutton, L. R., Lawrence, M., Chen, X., Ji, Z., \& Zeleke, W. (2017). Understanding the self in individuals with autism spectrum disorders (ASD): A review of literature. Frontiers in psychology, 8, 1422.

61. Schredl, M. (2017). Theorizing about the continuity between waking and dreaming: Comment on Domhoff (2017).

62. Kramer, M. (1991). The nightmare: A failure in dream function. Dreaming, 1(4), 277.

63. Buckley, A. W., Rodriguez, A. J., Jennison, K., Buckley, J., Thurm, A., Sato, S., \& Swedo, S. (2010). Rapid eye movement sleep percentage in children with autism compared with children with developmental delay and typical development. Archives of pediatrics $\mathcal{E}$ adolescent medicine, 164(11), 1032-1037.

64. Havdahl, K. A., von Tetzchner, S., Huerta, M., Lord, C., \& Bishop, S. L. (2016). Utility of the child behavior checklist as a screener for autism spectrum disorder. Autism Research, 9(1), 33-42.

65. Levin, R., \& Nielsen, T. (2009). Nightmares, bad dreams, and emotion dysregulation: A review and new neurocognitive model of dreaming. Current Directions in psychological science, 18(2), 84-88.

66. Fisher, C., Byrne, J., Edwards, A., \& Kahn, E. (1970). A psychophysiological study of nightmares. Journal of the American Psychoanalytic Association, 18(4), 747-782.

67. Lansky, M. R., \& Bley, C. R. (1995). Posttraumatic nightmares: Psychodynamic explorations. Analytic Press, Inc.

68. Simor, P., Horváth, K., Gombos, F., Takács, K. P., \& Bódizs, R. (2012). Disturbed dreaming and sleep quality: altered sleep architecture in subjects with frequent nightmares. European archives of psychiatry and clinical neuroscience, 262(8), 687-696. 